\title{
The best start for infants and young children in the WHO European Region
}

\author{
By Rachel Elsom, Kim Fleischer Michaelsen and Lawrence T. Weaver
}

\begin{abstract}
The present article highlights the importance of good complementary feeding practices in achieving optimum health, growth and development of infants and young children. A review of current infant and young child feeding practices in the WHO European Region, focusing particularly on countries of the former Soviet Union and Central Asian Republics, has identified a number of nutritional recommendations from the former Soviet era which differ from international standards. Other countries have no nutrition and feeding guidelines for this age group. A WHO Working Group was therefore established to produce updated recommendations on complementary feeding, which are appropriate for the WHO European Region. The publication "Nutrition and feeding guidelines for infants and young children in the WHO European Region, with emphasis on the Former Soviet Countries", is due to be published in autumn 2000.
\end{abstract}

\section{Introduction}

Optimum nutrition and good feeding of infants and young children are amongst the most important determinants of their health, growth and development. Good feeding practices will prevent malnutrition and early growth retardation, e.g. stunting, which is common in some parts of the WHO European Region. Poorly fed children have greater rates and severity of enteric and other infections, and they are at risk of dying prematurely. There is evidence that poor infant nutrition has longterm health consequences and plays a role in the development of some noncommunicable diseases in adults. Furthermore, micronutrient deficiencies especially of iron and iodine, are associated with delayed motor development and impaired cognitive function. Thus improvements in young child nutrition are desirable not only for their physical health and growth but also to reduce the risk of infection, to maximize psychomotor development and school performance and, in the long term, to improve adult health and life opportunities.

Rachel Elsom, Research Assistant, Dept of Child Health, University of Glasgow, Royal Hospital for Sick Children, Yorkhill, Glasgow, UK. Correspondence: Lawrence T. Weaver

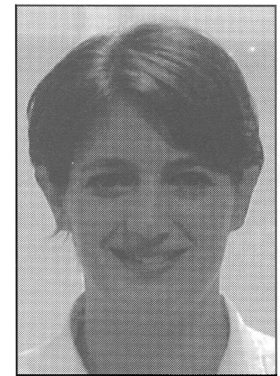

Despite the importance of correct infant and young child feeding practices, limited attention has been paid to the need for feeding guidelines based on scientific evidence. Guidelines on infant feeding practices in the eastern part of the European Region are based on former Soviet recommendations that are outdated and require revision. Moreover, a number of traditional practices within the Region appear to have adverse effects on nutritional status, particularly iron.

This article is based on that of the WHO/ Unicef publication "Feeding and nutrition of infants and young children. Guidelines for the WHO European Region with emphasis on the countries of the former Soviet countries" (1), which will be published during the autumn 2000. The main aim of that publication/this article is to provide the scientific rationale for the development of national nutrition and feeding recommendations from birth to the age of three years. These guidelines, if implemented, will have a positive impact on the health, growth and development of young children.

Kim Fleischer Michaelsen, Prof., Research Dept of Human Nutrition, The Royal Veterinary and Agricultural University, Frederiksberg, Denmark. Lawrence T. Weaver, Prof., Dept of Child Health, University of Glasgow, Royal Hospital for Sick Children, Yorkhill, Glasgow G3 8SJ, UK.
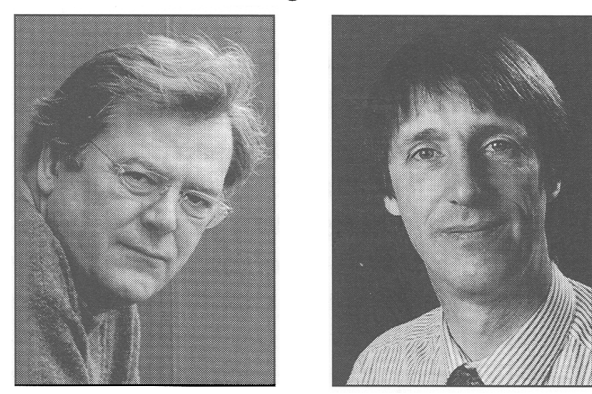

The publication is primarily intended for ministries of health and paediatricians and other health professionals, interested in nutrition, who are concerned with the public health of young children. Much of the information contained in this publication is relevant for most healthy young children living in the WHO European Region. However, the publication focuses on the prevention of the major public health problems that are found predominantly in the eastern part of the Region, but which are also common in ethnic minorities or children living in low income families in the west.

\section{Growth and programming \\ Growth faltering}

Infants and young children are very sensitive to growth faltering resulting from malnutrition. In populations where nutritional problems, such as stunting, are prevalent, it is common for both weight and height to deviate progressively from the growth reference during the 6-18 month old period, which is also the period of complementary feeding. The quality of complementary feeding is a major cause. It is possible that after this period, the capacity for catch-up in linear growth is limited, at least at the population level.

\section{Programming}

There is increasing evidence that a number of environmental factors that influence early human growth and development have long-term biological or behavioural effects. Examples include the relationship between the intra-uterine environment and adult cardiovascular disease (2), chronic bronchitis and hypertension; and an association between respiratory infection in infancy and chronic lung disease in 
adult life. It has been proposed that there are critical periods when environmental factors such as disturbances in nutritional metabolism, may significantly alter the developmental process from its genetic trajectory. This phenomenon is termed "programming".

Thus, the early human environment encompassing the intra-uterine period and first 18 months of life includes the most critical periods in development. According to the Barker hypothesis, sub-optimal nutrition during intra-uterine life will not only produce adverse effects in the short term but will also have long-term consequences for health in childhood into adulthood. It is therefore vital to ensure good maternal nutrition immediately prior to conception and during pregnancy to safeguard optimal fetal growth and development. After birth, these foundations should be built on by ensuring that the infant is breastfed and that complementary foods are introduced at an appropriate age and provide the best nutrition possible for the growing child.

\section{Problems in the $\mathrm{WHO}$ European Region}

Historically, life expectancy in the WHO European Region has been high and increasing. However, since the disintegration of the Soviet Union there has been an unprecedented and dramatic decrease in life expectancy at birth in countries which were formerly part of it. There are a number of factors contributing to this: infant and under five mortality remains high; rates of exclusive breastfeeding are still low in many countries; and iron deficiency anaemia is a major concern across the Region. Furthermore, it is estimated that $32 \%$ of the population of the WHO European Region is living in poverty. While the impact of poverty is greatest in eastern Europe, there is evidence of growing inequalities in western Europe. Poverty is associated with malnutrition and other adverse health effects.

\section{Infant and under 5 mortality}

Since the 1970 s, there has been a steady decrease in infant and under five mortality rates in the European Region. However, as shown in Figure 1, rates differ considerably across the Region. While the EU and Nordic averages have dropped to just 5 deaths per 1000 live births in 1995, the figures for Commonwealth of Independent States (CIS) and especially CAR remain significantly higher than in the rest of the Region, at 23 and 33 respectively. The mortality rates in Central and Eastern Europe (CEE) and in the Balkans fall between these two extremes at around 10-20/

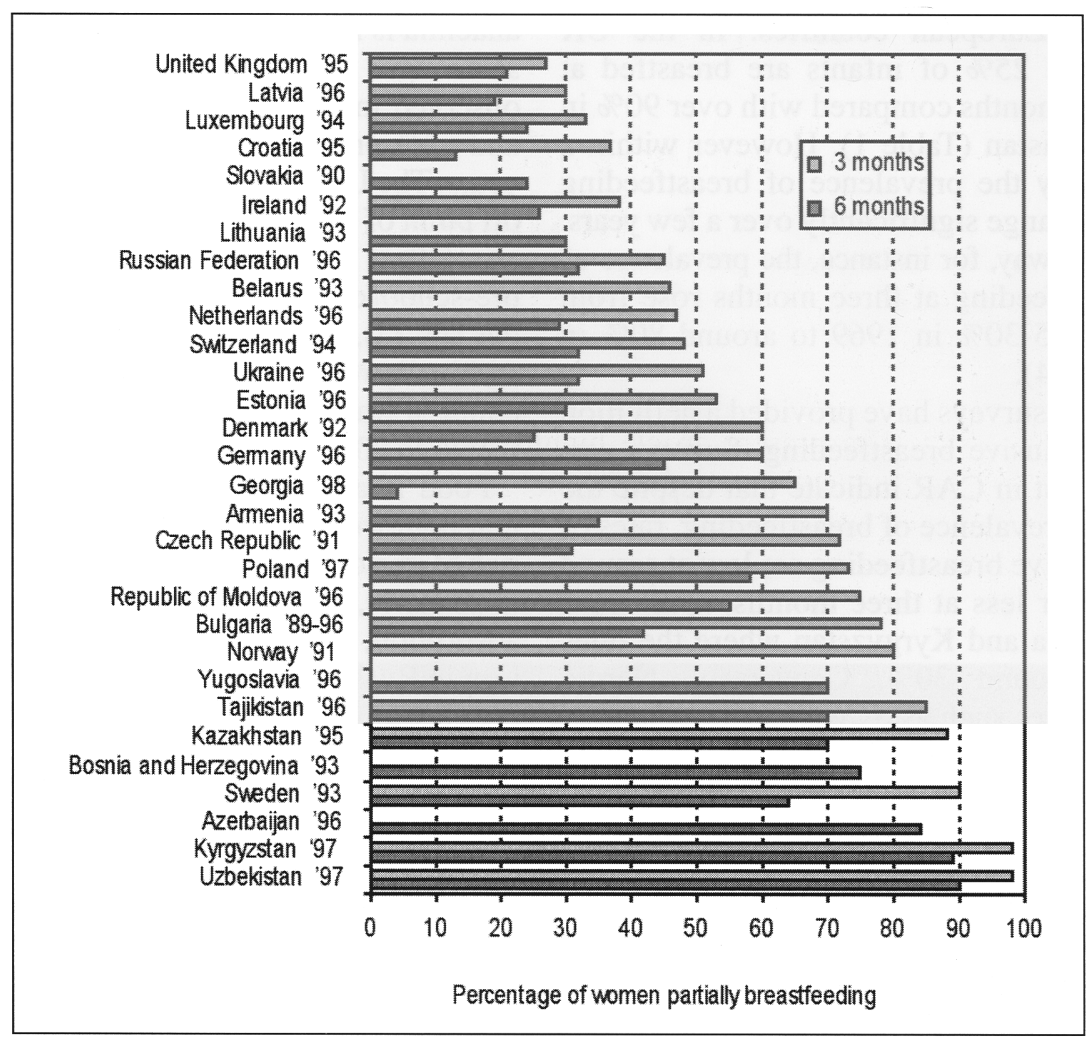

Fig. 1. Infant mortality rate (IMR) and under 5 mortality rate per 1000 live births in Europe, 1993-1996.

1000 live births in infants and under fives.

In countries with high mortality rates, the primary cause of infant deaths are infectious diseases. Poor nutritional status compromises the immune function of young children and makes them more susceptible to infections, including acute respiratory infections, diarrhoeal diseases and vaccine-preventable diseases such as tuberculosis. In Central Asian Republics (CAR), seven out of ten deaths are due to these illnesses, often in combination, and among children under five years. Pneumonia, in particular, is responsible for between 30 and $50 \%$ of all infant deaths. In contrast, the main cause of infant deaths in western European countries are congenital malformations.

\section{Prevalence of breastfeeding}

Owing to a lack of comprehensive and comparable data and of standardized international definitions, it is difficult to make a general statement about the prevalence of breastfeeding in the WHO European Region. Data on the percentage of breastfed infants in Table 1 should be interpreted with caution, because the survey methodology varied and a description of how the surveys were carried out was not always reported.

With these caveats, it can be seen that breastfeeding rates vary dramatically bet-
Table 1. Proportion of infants being breastfed at 3 and 6 months in different European countries.

\begin{tabular}{|c|c|c|c|}
\hline & Year & $3 \mathrm{mo}$ & $6 \mathrm{mo}$ \\
\hline United Kingdom & 95 & 27 & 21 \\
\hline Latvia & 96 & 30 & 19 \\
\hline Luxembourg & 94 & 33 & 24 \\
\hline Croatia & 95 & 37 & 13 \\
\hline Slovakia & 90 & - & 24 \\
\hline Ireland & 92 & 38 & 26 \\
\hline Lithuania & 93 & - & 30 \\
\hline Russian Federation & 96 & 45 & 32 \\
\hline Belarus & 96 & 46 & - \\
\hline Netherland & 96 & 47 & 29 \\
\hline Switzerland & 94 & 48 & 32 \\
\hline Ukaraine & 96 & 51 & 32 \\
\hline Estonia & 96 & 53 & 30 \\
\hline Denmark & 92 & 60 & 25 \\
\hline Germany & 96 & 60 & 45 \\
\hline Georgia & 98 & 65 & 4 \\
\hline Armenia & 93 & - & 37 \\
\hline Czech Republic & 91 & 72 & 31 \\
\hline Poland & 97 & 73 & 58 \\
\hline Rep of Moldavia & 96 & 75 & 55 \\
\hline Bulgaria & $89-96$ & 78 & 42 \\
\hline Norway & 91 & 80 & - \\
\hline Yugoslavia & 96 & - & 70 \\
\hline Tajikistan & 96 & 85 & 70 \\
\hline Kazakhstan & 95 & 88 & 70 \\
\hline Bosnia and Herzegovina & 93 & - & 75 \\
\hline Sweden & 93 & 90 & 64 \\
\hline Azerbeijan & 96 & - & 84 \\
\hline Kyrgyzstan & 97 & 98 & 89 \\
\hline Uzbekistan & 97 & 98 & 90 \\
\hline
\end{tabular}

Source: WHO/Unicef 1999 (3). 
ween European countries. In the UK around $25 \%$ of infants are breastfed at three months compared with over $90 \%$ in Uzbekistan (Table 1). However within a country the prevalence of breastfeeding can change significantly over a few years. In Norway, for instance, the prevalence of breastfeeding at three months rose from only $25-30 \%$ in 1969 to around $80 \%$ in 1991 (4).

Few surveys have provided a definition of exclusive breastfeeding. Surveys carried out in CAR indicate that despite the high prevalence of breastfeeding, rates of exclusive breastfeeding are low at around $10 \%$ or less at three months, apart from Georgia and Kyrgyzstan where the rates are around $30 \%$. Conversely, Nordic countries such as Sweden have relatively high rates of exclusive breastfeeding both at three and six months.

Greater efforts are needed to increase the rates of exclusive breastfeeding during the first few months of life. This is especially important for vulnerable groups such as ethnic minorities and low-income families living in areas with poor hygiene, sanitation and water supply.

\section{Prevalence of anaemia}

In Europe information on the prevalence of iron deficiency in children is limited. Most studies have only investigated the prevalence of anaemia, usually by measuring haemoglobin levels, and not its aetiology, although iron deficiency is likely to be the most common cause. Comparisons are further hindered by the use of different cut-off points and different age groups. While all studies define severe anaemia as a $\mathrm{Hb}<70 \mathrm{~g} / \mathrm{L}$ the cut-off point for mild anaemia in children under five years is $110 \mathrm{~g} / \mathrm{L}$ in some studies and $120 \mathrm{~g} / \mathrm{L}$ in others. The highest prevalence of anaemia has been reported in CAR where more than half of the children under three years had $\mathrm{Hb}$ less than $120 \mathrm{~g} / \mathrm{L}$ (Table 2). It should be pointed out however that only a small proportion of cases have severe anaemia $(\mathrm{Hb}<70 \mathrm{~g} / \mathrm{L})$. In western Europe

Table 2. Prevalence of anaemia in children aged under 5 years (1).

\begin{tabular}{lrrrr}
\hline & $\begin{array}{c}\text { Severe } \\
\%\end{array}$ & $\begin{array}{c}\text { Moderate } \\
\%\end{array}$ & $\begin{array}{c}\text { Mild } \\
\%\end{array}$ & $\begin{array}{c}\text { Total } \\
\%\end{array}$ \\
\hline Uzbekistan & 1 & 2 & 34 & 61 \\
Kazakstan & 5 & 34 & 30 & 69 \\
Kyrgyzstan & 1 & 24 & 24 & 50 \\
Azerbaijan & 3 & 32 & 31 & 66 \\
Armenia & 0 & 2 & 16 & 18 \\
Bosina & 1 & 3 & 19 & 26 \\
United Kingdom & & & & 12 \\
Unted Kingdom & & & & 6
\end{tabular}

anaemia is less frequent in children of the same age: a $12 \%$ prevalence has been observed in UK children aged 1-2 years and a $6 \%$ prevalence in children aged $2-4$ years. The UK survey however used a cutoff point of $110 \mathrm{~g} / \mathrm{L}$. Iron deficiency anaemia $(\mathrm{Hb}<110 \mathrm{~g} / \mathrm{L})$ occurs in $10-30 \%$ of pre-school children living in inner cities of the UK (5), and the prevalence among a nationally representative sample of Asian children was significantly higher than this (between 20 and 45\%) (6).

Food intake data from Russia suggest that both women and children are at high risk of iron deficiency. Grain products rich in phytates, which inhibit non-haem iron absorption, are the major food source of iron in Russia (7). Moreover the reported high intakes of tea and low consumption of vitamin $\mathrm{C}$ also compromise the bioavailability of iron present in their diet. There is a need for studies to identify the possible causes of the high prevalence of mild and moderate anaemia in some parts of the WHO European Region, such as too early introduction of cows' milk and tea.

\section{Breastfeeding}

Human milk is the best food for babies and provides all the nutrients needed for about the first six months of life. WHO/UNICEF recommendations for the WHO European Region are (1):

- All infants should be exclusively breast-fed from birth to about six months, but not less than four months; additional foods and fluids are not necessary during this time, and if introduced will hinder the initiation and continuation of breastfeeding, which offers maximum benefits to both mother and infant;

- Breastfeeding should preferably continue beyond the first year of life, and in populations with high rates of infection continued breastfeeding through the second year and longer is likely to benefit the young child.

\section{Breastfeeding - infectious disease} Human milk contains nutrients that serve the unique needs of the human infant (e.g. certain essential polyunsaturated fatty acids, certain milk proteins, and iron in a readily absorbable form). It also contains immunological and bioactive substances, absent from commercial infant formulas, which confer protection from bacterial and viral infections, aid growth, and enhance physiological and behavioural development of the newborn. These effects have been evaluated in several review papers (8-10).

Breastfeeding protects infants from infections by two mechanisms. First it lowers or eliminates exposure to bacterial pathogens transmitted by contaminated food and fluids. Second, human milk contains antimicrobial factors and other substances that strengthen the immature immune system and protect the digestive system of the newborn infants, and thereby confer protection against infections, particularly those of the gastrointestinal and respiratory tracts. Colostrum (milk produced in the first few days after birth) is especially rich in protective proteins.

The principal immunoproteins in human milk are secretory immunoglobulin A ( $\operatorname{Ig} \mathrm{A})$ and lactoferrin. The former acts at mucosal surfaces to protect them from injury by, or uptake of ingested microbial antigens and the latter is an iron-binding protein that competes with bacteria for iron, reducing bacterial viability and thereby the risk of enteric infections, particularly those caused by Escherichia coli and Staphylococci. These immunological factors are not present in commercial infant formula or complementary foods. Formula-fed infants therefore enjoy less protection against infection. Human milk also contains many other defence and trophic factors which may play a role in the protection and matura tion of the digestive tract.

There is abundant evidence that exclusive breastfeeding for around the first six months reduces both morbidity and mortality, and these beneficial effects are more pronounced where infection rates are greatest and hygiene and sanitation are poor (11-14). Furthermore, the concentrations of anti-infective substances in breast-milk are sustained beyond the first year of life and continue to offer significant protection against infection thereafter (11,15-17).

The evidence that breastfeeding is protective against infectious disease is greatest for diarrhoeal disease: formulafed infants suffer a significantly higher number of diarrhoeal episodes than infants who are breastfed. There is also strong evidence that breastfeeding protects against lower respiratory disease. In a recent study (18), breastfeeding was found to protect young children against pneumonia, especially in the first months of life. Formula-fed infants were 17 times more likely to be admitted to hospital for pneumonia than breastfed infants. Furthermore, a number of studies have demonstrated a protective effect of breastfeeding against otitis media (19-21).

Most of the protective effects of breastfeeding against infectious disease are passive, i.e. immuno-protective factors in breast-milk protect the mucosal surfaces of the gastrointestinal and respiratory tract and thereby decrease the risk of infections. However, there is also evidence that 
breast-milk has an active influence on the infant's immune system. At four months, the thymus gland of breastfed infants is twice the size of that in formula-fed infants (22), and several studies have indicated that immune-related diseases such as IDDM, Crohn's Disease and ulcerative colitis, are less common in breastfed than formula-fed infants (9).

\section{Breastfeeding - obesity}

It has been argued that breastfeeding prevents adiposity later in childhood. In a recent study from Germany (23), the body mass index (BMI) of 9,357 children aged 5-6 years was compared to their breastfeeding history. Those that had been breastfed for longest were significantly less likely to be obese at 5 to 6 years of age.

\section{Breastfeeding - cognitive function} It has been postulated that suboptimal nutrition during the vulnerable phase of brain development (between the third trimester and second year of life) may have a permanent adverse effect on motor and mental development. A meta-analysis of 20 studies has investigated the relationship between early infant diet and cognitive function in childhood (24). Breastfeeding was found to have a significant positive effect on intelligence quotient (IQ) scores. Children who had been breastfed as infants had a 5.3 point advantage over those who were formula-fed, before adjustment for confounders. After controlling for confounding factors, this advantage decreased to 3.2 points.

\section{Supporting, protecting and promoting breastfeeding}

As highlighted above, breastfeeding confers a wide range of benefits to both mother and infant, in both the short and long-term. However, current legislation and health care practices are often at odds with recommendations on the best ways to establish breastfeeding.

The International Code of Marketing of Breast-milk Substitutes was adopted by the World Health Assembly (WHA) in 1981 as a "minimum requirement" to be enacted "in its entirety" in "all countries". The Code does not try to stop the availability or sale of breastmilk substitutes, but it does seek to stop activities which persuade people to use them. Most importantly, it also protects artificially fed children by ensuring safe labels and ensuring decisions are made on the basis of truly independent health advice. The key provisions are summarized in Box 1. Governments are urged to implement the Code and subsequent WHA resolutions, and companies that manufacture breast-

\section{Box 1. Summary of the International code of marketing of breast-milk substitutes.}

1. No advertising of any breast-milk substitutes (any product marketed or represented to replace breast-milk) or feeding bottles or teats.

2. No free samples or free or low cost supplies to mothers.

3. No promotion of products in or through health care facilities.

4. No contact between marketing personnel and mothers (mothercraft nurses or nutritionists paid by companies to advise or teach).

5. No gifts or personal samples to health workers or their families.

6. Product labels should be in an appropriate language and no words or pictures idealizing artificial feeding (pictures of infants or health claims) should be used.

7. Only scientific and factual information to be given to health workers.

8. Governments should ensure that objective and consistent information is provided on infant and young child feeding.

9. All information on artificial infant feeding, including labels, should clearly explain the benefits of breastfeeding and warn of the costs and hazards associated with artificial feeding.

10. Unsuitable products, e.g. sweetened condensed milk, should not be promoted for babies.

11. All products should be of a high quality and take account of the climatic and storage conditions of the country where they are used.

12. Manufacturers and distributors should comply with the Code (and all the Resolutions) independently of any government action to implement it.

Box 2. Operational targets of the Innocenti Declaration, 1990.

By the year 1995 all governments should have achieved the following operational targets:

1. Appointed a national coordinator and appropriate authority, and established a multisectoral national breastfeeding committee composed of representative from relevant government departments, NGOs, and health professional associations.

2. Ensured that every facility providing maternity services fully practises all ten steps to successful breastfeeding set out in the joint WHO/UNICEF statement "Protection, promotion and supporting breastfeeding: the special role of maternity services".

3. Taken action to give effect to the principles and aim of all Articles of the International Code of Marketing of Breast-milk Substitutes and subsequently relevant World Health Assembly resolutions in their entirety.

4. Enacted imaginative legislation protecting the breastfeeding rights of working women and established means for its enforcement.

Box 3. The BFHI 10 steps to successful breastfeeding.

1. Have a written breastfeeding policy that is routinely communicated to all health care staff.

2. Train all health care staff in skills necessary to implement this policy.

3. Inform all pregnant women about the benefits and management of breastfeeding.

4. Help mothers initiate breastfeeding within a half-hour of birth.

5. Show mothers how to breastfeed, and how to maintain lactation even if they should be separated from their infants.

6. Give newborn infants no food and drink other than breast-milk, unless medically indicated.

7. Practise rooming-in - allow mothers and infants to remain together $-24 \mathrm{~h}$ a day.

8. Encourage breastfeeding on demand.

9. Give no artificial teats or pacifiers (also called dummies or soothers) to breastfeeding infants.

10. Foster the establishment of breastfeeding support groups and refer mothers to them on discharge from the hospital or clinic.

milk substitutes are urged to adhere to it. Furthermore, health professionals should have good knowledge of the provisions of the Code because they have a number of responsibilities under it.

In 1990, the Innocenti Declaration on the Protection, Promotion and Support of Breastfeeding was produced and adopted by participants at the WHO/UNICEF policy-makers' meeting on "Breastfeeding in the 1990s: A Global Initiative". The
Declaration sets a global goal and has become a guide for governments aiming to promote breastfeeding (Box 2).

To help countries reach the global breastfeeding goal stated in the Innocenti Declaration, WHO and UNICEF jointly launched the Baby-Friendly Hospital Initiative (BFHI) in 1991. At the foundation of the BFHI are the 10 steps to successful breastfeeding (Box 3). These summarize the maternity practices necessary to estab- 
lish a supportive environment for women wishing to breastfeed and thereby bring about improvements in the incidence and duration of breastfeeding. The BFHI also prohibits free and low-cost infant formula supply in hospitals, and demands the elimination of advertising and promotional activities for infant formula or feeding by bottle. To become a baby-friendly hospital every facility that contributes to maternity services and to the care of newborn infants must implement the ten steps.

Reinforcing this, the 45th World Health Assembly 1992 urged Member States to encourage and support all public and private health facilities providing maternity services so that they become "babyfriendly". It should be recognized that mothers not choosing to breastfeed will also benefit from baby-friendly practices such as skin-to-skin contact, rooming-in, and feeding on demand.

The effect of the BFHI on the initiation and duration of breastfeeding, and the prevalence of infection has been examined in a large-scale study in Belarus (Kramer, personal communcication). Thirty two of the country's hospitals were randomized to either implement the BFHI training or to continue with traditional practices, for a 9-12 month period. 17,795 mothers were recruited and followed up at 1,2,3,6,9 and 12 months. The major outcome measures were duration of breastfeeding and episodes of gastrointestinal and respiratory infections. Results are due to be published in 2000 .

\section{Complementary feeding}

As the baby grows and becomes more active, breast-milk alone is insufficient to meet the full nutritional needs of the infant. Complementary foods - foods and fluids given in addition to breast-milk - are needed to fill the gap in energy and iron and other essential nutrients, between what is provided by exclusive breastfeeding and the total nutritional requirements of the infant. Infants do not have the physiological maturity to progress directly from exclusive breastfeeding to family foods and specially adapted foods are therefore required. During the period of transition from exclusive breastfeeding to the cessation of breastfeeding, infants gradually become accustomed to eating family foods, and by about one year children are physically capable of consuming family foods that have been mashed or cut into small pieces.

The age during which complementary foods are introduced is a particularly sensitive time in infant development. This transition is associated not only with increasing and changing nutrient require- ments, but also with rapid growth, physiological maturation and development of the infant. Poor nutrition and less than optimum feeding practices during this critical period may increase the risk of growth faltering (wasting and stunting) and nutritional deficiencies, especially of iron, and may have longer term adverse effects on health and mental development. Thus, timely introduction of appropriate complementary foods which promotes good health and growth of infants and young children, should be given a high priority.

Starting complementary feeding too soon has its dangers because:

- Breast-milk can be displaced by complementary foods, leading to decreased breast-milk production and thereby insufficient energy and nutrient intake by the infant.

- Infants are exposed to microbial pathogens present in foods and fluids, which are potentially contaminated thereby increasing the risk of diarrhoeal disease and consequently malnutrition.

- The risks of diarrhoeal and food allergic disease are increased because of intestinal immaturity, and these increase the risk of malnutrition.

- Mothers become fertile more quickly as decreased suckling reduces the time period that ovulation is suppressed. This will lead to an increase in the number of births and a decrease in the interval between successive pregnancies, in populations where other methods of contraception are not readily available or acceptable.

There will also be problems if complementary foods are introduced too late because:

- Inadequate provision of energy and nutrients from breast-milk alone may lead to growth faltering (e.g. stunting) and malnutrition (e.g. anaemia).

- Micro-nutrient deficiencies may develop, especially iron and zinc, due to inability of breast-milk to meet requirements.

- The optimal development of motor skills, such as chewing, and the infant's acceptance of new tastes and textures may not be ensured.

It is therefore necessary to introduce complementary foods at the appropriate developmental stages. For the WHO European Region it is recommended that complementary foods are introduced at about six months of age. Some infants may need complementary foods before six months of age, but they should not be introduced before four months. Signs that complementary foods should be introduced before six months are that the baby, in the absence of obvious disease, is not gaining weight adequately, or shows hunger after unrestricted breastfeeding.

\section{Energy and nutrient density of complementary foods}

Infants and young children have an energy intake (per kg body weight) around two to three times greater than that of adults. Because they have to ingest large amounts of energy, a key determinant of energy intake is the energy density of complementary foods. If the energy density is too low it may result in an energy deficit and consequently poor growth. Adding fat or sugar are ways of increasing the energy density without increasing the viscosity of the food, and because fat is very energy dense, it is the most efficient way of achieving this. The average energy density of complementary foods should be higher than that of breast-milk (i.e. $>2.8 \mathrm{~kJ} / \mathrm{g}$ ), and ideally closer to $4.2 \mathrm{~kJ} / \mathrm{g}$. Energy intake is also increased through more frequent meals and an increased intake of breast-milk. Conversely, energy intake will be reduced by a high viscosity of complementary food which is typically the result of a high starch content. The addition of water to reduce viscosity results in a reduction in energy density.

Energy intake is further influenced by gastric capacity which determines the volume an infant can ingest during one meal. If the energy density of meals is low, the infant will require a large volume of food to satisfy energy requirements and this may exceed the limit set by the infant's gastric capacity. It has been estimated that breastfed infants older than eight months should receive at least three meals of complementary foods per day and that if the energy density of the diet is less than $4.2 \mathrm{~kJ} / \mathrm{g}$, more than three meals are needed. For those infants receiving little or no breast-milk (or suitable alternative formula), at least four meals per day, or very energy dense food, is required (25).

The quantity and bioavailability of micronutrients in breast-milk and complementary foods is also a vital determinant of infant and young child growth and development. Micronutrient density is defined as the amount of a nutrient per energy unit e.g. $100 \mathrm{~kJ}$, or per weight unit, e.g. $100 \mathrm{~g}$, while bioavailability is the absorbability of nutrients and their availability for utilization for metabolic purposes.

There are major differences between the nutrient density (amount/100 kJ) and bioavailability of micro-nutrients in animal products and plant-derived foods. Per unit energy, animal products usually contain 
more of certain nutrients such as retinol, vitamins $D$ and $E$, riboflavin, vitamin $B_{12}$, calcium and zinc. The iron content of some animal products is high (e.g. liver, meat, fish, and poultry) whereas that of others is low (milk and dairy products). In contrast, the density of thiamin, vitamin $\mathrm{B}_{6}$, folic acid, and vitamin $\mathrm{C}$ is generally higher in plants and some, like legumes and maize, also contain substantial amounts of iron. However, in general the bioavailability of minerals from plant products is poor, compared with that from animal products.

Micro-nutrients that have poor bioavailability when consumed in plant products include iron, zinc, calcium, and $\beta$-carotene in leafy and some other vegetables. In addition, the absorption of $\beta$-carotene, retinol and other fat soluble vitamins is impaired when diets are low in fat.

A diet with high nutrient bioavailability is diverse and contains generous amounts of legumes and foods rich in vitamin $C$, combined with small amounts of meat, fish and poultry. Diets with low nutrient bioavailability consist mainly of cereals, legumes, roots and negligible quantities of meat, fish, or vitamin C-rich foods.

\section{Iron deficiency}

Iron deficiency is one of the commonest nutritional deficiencies world-wide and it is estimated that $43 \%$ of the world's infants and children under the age of four years suffer from iron deficiency anaemia (IDA) (26).

The main consequences of IDA are shown in Table 3. In infants and young children (under two years old) the consequence of IDA of greatest concern is the possible impairment of mental and psychomotor development. This is likely to arise because the period of complementary feeding, which represents the peak prevalence of IDA in children, coincides with a period of high growth velocity and the latter part of the spurt in brain growth when cognitive and motor development takes place. It is unclear whether iron supplementation can reverse the developmental delay caused by IDA during infancy and childhood, and therefore prevention through dietary modification and other strategies, should be given a higher priority than detection and treatment.

Optimal iron stores at birth are important for the prevention of iron deficiency in the infant and young child. Iron stores are gradually depleted over the first six months of life after which the size depends on dietary iron intake. If the mother has severe iron deficiency anaemia, infant iron stores at birth will be small (27). However, moderate iron deficiency in the mother does not seem to influence the iron status of the infant. Infant iron stores are also influenced by the amount of blood transferred from the placenta to the infant at delivery before ligation of the umbilical cord. Therefore, to optmize infant iron stores at birth, women should be advised to eat an iron-rich diet during pregnancy, and at birth, the umbilical cord should not be clamped and ligated until it stops pulsating.

The young child is especially vulnerable to the development of iron deficiency during the period from 6 to 24 months, when the increased nutritional needs resulting from rapid growth, are combined with a diet that may be low in iron and vitamin $\mathrm{C}$, with a high intake of unmodified cows' milk and other inhibitors of iron absorption. Dietary recommendations concerning iron are therefore particularly important during the complementary feeding period, and prevention of iron deficiency should be given a high priority by ministries of health.

Poor complementary feeding practices are a partial explanation of the poor iron status of infants and young children in the European Region, particularly in the countries of the former Soviet Union and CAR. The main findings of the surveys on feeding practices for infants and young children in countries throughout the WHO European Region are that:

- Exclusive breastfeeding

is not widely practised

- Cows' milk is introduced too early

- Liquids, particularly tea, are introduced too early

- Semi-solid foods

are introduced too early

- Meat and liver are introduced too late.

The too early introduction of unmodified cows' milk is the most important nutritional risk factor for iron deficiency anaemia. This is because cows' milk has a low iron content and in contrast to breast-milk, its iron is poorly absorbed. Furthermore, several studies suggest that early introduction of unmodified cows' milk can provoke gastrointestinal bleeding (28-29) and thereby have a negative effect on iron status. Therefore, unmodified cows' milk should not be introduced as a drink before the age of 9 months, but can be used in small quantities in the preparation of complementary foods from 6 to 9 months of age. Thereafter, if infants are no longer breastfed, cows' milk can gradually be introduced as a drink.

The early introduction of tea (black, green and herbal), which is common throughout the European Region, also has a negative effect on the iron status of infants and young children. Teas contain
Table 3. Sources and functions of iron and effects of iron deficiency.

Important sources of iron

- Breast-milk

- Liver and organ meats

- Other meats and poultry

- Egg yolk

- Sardines and mackerel

- Wholegrain cereals and breads

- Legumes

- Spinach

- Iron-fortified infant foods

Iron pools and function

- In the haemoglobin of red blood cells, which transport oxygen from the lungs to the tissues

- In the myoglobin in muscle which stores the oxygen needed for muscle contraction

$\checkmark$ In the liver and reticuloendothelial system as an iron store

Effects of iron deficiency

$\checkmark$ Higher risk of maternal mortality

- Fetal growth retartation

- Increased prenatal and perinatal mortality

- Lowered physical activity

- Reduced appetite

- Possible impairment of mental and psychomotor development

- Possible increased susceptibility to infection

tannins and other compounds which bind iron thereby reducing its bioavailability. Therefore, tea should be avoided until at least two years of age, and thereafter it should be avoided at mealtimes.

\section{Conclusions}

Because of the diverse cultural habits across the Region, the foods which constitute the customary diet of infants in the WHO European Region are extremely varied. In order to address these issues effectively it will be necessary for ministries of health to produce national guidelines that are suited to the local situation. However, before these guidelines can be developed, local conditions should be assessed. It is strongly recommended that ministries of health, possibly jointly with ministries of food and agriculture, initiate regular monitoring of the health and growth of infants and young children which become an integral part of the national health and nutrition information system. 


\section{REFERENCES}

1. WHO/UNICEF: Feeding and Nutrition Guidelines for Infants and Young Children in the WHO European Region, with emphasis on the former Soviet Countries. WHO Copenhagen (In preparation).

2. Barker DJP (ed):. Fetal and Infant Origins of Adult Disease. London: BMJ, 1992.

3. WHO/UNICEF: Comparative Analysis of Implementation of the Innocenti Declaration in WHO European Member States. Monitoring Innocenti targets on the protection, promotion and support of breastfeeding. WHO Copenhagen, 1999. EUR/ICP/LVNG 010102.

4. Heiberg Endersen E, Helsing E. Changes in breastfeeding practices in Norwegian maternity wards: national surveys 1973,1982 and 1991. Acta Paediatr 1995; 84:719-24.

5. Gregory JR et al: National diet and nutrition survey children aged $1.5-4.5$ years. Vol 1 Report of the Diet and Nutrition survey, HMSO 1995.

6. Lawson MS et al: Iron status of Asian children aged 2 years living in England. Arch of Dis Childh 1998;78:420-6.

7. Kohlmeier L: Deficient dietary iron intakes among women and children in Russia: evidence from the Russian Longitudinal Monitoring Survey. Am J Publ Health 1998;88:576-80.

8. American Academy of Pediatrics: Working Group on Breastfeeding. Breastfeeding and the use of human milk. Pediatrics 1997;100:1035-9.

9. Heinig MJ, Dewey KG: Health advantages of breastfeeding for infants: a critical review. Nutr Res Rev 1996;9:89-110.

10. Golding J: Breastfeeding: benefits and hazards. Methodology and summary of results. Early Human Development 1997; 49:Suppl S45-74.

11. Victora CG, Smith,PG, Vaughan JP, Nobre LC Lombardi C, Teixeira AM, Fuchs SM, Moreira
LB, Gigante LP, Barros FC: Evidence for protecting by breastfeeding against infant deaths from infectious diseases in Brazil. Lancet 1987;2:319-22.

12. Howie PW, Forsyth JS, Ogston SA, Clark A, Florey du V C: Protective effect of breastfeeding against infection. Br Med J 1990; 300: 11-6.

13 Forsyth JS: The relationship between breastfeeding and infant health and development. Proc Nutr Soc 1995;54:407-18.

14. Wilson $\mathrm{AC}$ et al: Relation of infant diet to childhood health: seven year follow up of cohort of children in Dundee infant feeding study. Br Med J 1998;346:21-5.

15 Briend A, Bari A: Breastfeeding improves survival, but not nutritional status, of 12-35 month old children in rural Bangladesh. Eur J Clin Nutr 1989;43:603-8.

16. Mølbak K, Gottschau A, Aaby P, Højlyng N, Ingholt L, Dasilva APJ: Prolonged breastfeeding, diarrhoeal disease, and survival of children in Guinea-Bissau. Br Med J 1994;308:1403-6.

17. Mitra AK, Rabbani F: The importance of breastfeeding in minimizing mortality and morbidity from diarrhoeal diseases: the Bangladesh perspective. J Diarrhoeal Disease Res 1995; 13:1-7.

18. César JA, Victora CG, Barros FC, Santos IS, Flores JA: Impact of breastfeeding on admission for pneumonia during postneonatal period in Brazil: nested case-control study. Br Med J 1999;318:1316-20.

19. Teele DW, Klein JO, Rosner B: Greater Boston Otitis Media Study Group. Epidemiology of otitis media during the fist seven years of life in children in greater Boston: a prospective, cohort study. J Inf Dis 1989;160:83-94.

20. Duncan B, Ey J, Holberg CJ, Wright AL, Martinez FD, Taussig LM: Exclusive breastfeeding for at least 4 months protects against otitis media. Pediatrics 1993;91:867-72.

21. Owen MJ, Baldwin CD, Swank PR, Pannu AK Johnson DL, Howie VM: Relation of infant feeding practices, cigarette smoke exposure, and group child care to the onset and duration of otitis media with effusion in the first two years of life. J Pediatr 1993;123:702-11.

22. Hasselbalch H, Jeppesen DL, Engelmann MDM, Michaelsen KF, Nielsen MB: Decreased thymus size in formula-fed infants compared with breastfed infants. Acta Paediatr 1996; 85:1029-32.

23. Von Kries R, Koletzko B, Sauerwald T, von Mutius E, Barnert D, Grunert V, von Voss H: Breastfeeding and obesity: cross-sectional study. Brit Medl J 1999;319:147-50.

24. Anderson JW, Johnstone BM, Remley DT: Breastfeeding and cognitive development: a meta-analysis. Am J Clin Nutr 1999;70:525-35.

25. WHO/UNICEF/ORSTOM/UCDAVIS: Complementary Feeding of Young Children in Developing Countries: a review of current scientific knowledge. WHO Geneva, 1998. WHO/ NUT/98.1.

26. WHO: Preventing and controlling iron deficiency anaemia through primary health care: A guide for health administrators and programme managers. WHO, Geneva 1989.

27. Singla PN et al: Fetal iron status in maternal anaemia. Acta Paediatrica 1996; 85:1327-30.

28. Ziegler EE, Fomon SJ, Nelson SE, Rebouche CJ, Edwards BB, Rogers RR, Lehman LJ: Cow milk feeding in infancy: further observations on blood loss from the gastrointestinal tract. J Pediatr 1990;116:11-8.

29. Sullivan PB: Cows' milk induced intestinal bleeding in infancy. Arch of Dis Childh 1993; $68: 240-5$. 